\title{
Targeted mRNA degradation by double-stranded RNA in vitro
}

\author{
Thomas Tuschl, ${ }^{1-4,8}$ Phillip D. Zamore, ${ }^{1,4,5,8}$ Ruth Lehmann, ${ }^{6}$ David P. Bartel, ${ }^{1,7,8}$ \\ and Phillip A. Sharp ${ }^{3,7}$ \\ ${ }^{1}$ The Whitehead Institute for Biomedical Research, Cambridge, Massachusetts 02142, USA; ${ }^{3}$ Center for Cancer Research and \\ ${ }^{7}$ Department of Biology, Massachusetts Institute of Technology, Cambridge, Massachusetts 02139 USA; ${ }^{6}$ Howard Hughes \\ Medical Institute and The Skirball Institute, New York University Medical Center, New York, New York 10016, USA
}

\begin{abstract}
Double-stranded RNA (dsRNA) directs gene-specific, post-transcriptional silencing in many organisms, including vertebrates, and has provided a new tool for studying gene function. The biochemical mechanisms underlying this dsRNA interference (RNAi) are unknown. Here we report the development of a cell-free system from syncytial blastoderm Drosophila embryos that recapitulates many of the features of RNAi. The interference observed in this reaction is sequence specific, is promoted by dsRNA but not single-stranded RNA, functions by specific mRNA degradation, and requires a minimum length of dsRNA. Furthermore, preincubation of dsRNA potentiates its activity. These results demonstrate that RNAi can be mediated by sequence-specific processes in soluble reactions.
\end{abstract}

[Key Words: RNAi; post-transcriptional gene silencing; dsRNA]

Received September 20, 1999; revised version accepted October 28, 1999

Post-transcriptional gene silencing by double-stranded RNA (dsRNA), or RNA interference (RNAi), is a new tool for studying gene function in an increasing number of organisms (for reviews, see Montgomery and Fire et al. 1998; Fire 1999; Hunter 1999; Sharp 1999) including nematodes (Fire et al. 1998; Montgomery et al. 1998), fruit flies (Kennerdell and Carthew 1998; Misquitta and Paterson 1999), trypanosomes (Ngo et al. 1998), plants (Waterhouse et al. 1998), planaria (Sánchez-Alvarado and Newmark 1999), hydra (Lohmann et al. 1999), and zebrafish (Wargelius et al. 1999). The post-transcriptional silencing of endogenous genes following introduction of transgenes into plants (cosuppression; Vaucheret et al. 1998; Waterhouse et al. 1998; Baulcombe 1999), the fungus Neurospora (quelling; Cogoni et al. 1996; Cogoni and Macino 1999), flies (Pal-Bhadra et al. 1997, 1999), and mice (Bahramian and Zarbl 1999) may also be related to RNAi because antisense transcripts may be produced from transgenes, resulting in dsRNA formation.

The hallmark of RNAi is its specificity. dsRNA reduces expression of the gene from which the dsRNA sequence is derived, without detectable effect on the expression of genes unrelated in sequence (Fire et al. 1998;

Present addresses: ${ }^{2}$ Department of Cellular Biochemistry, Max-PlanckInstitute for Biophysical Chemistry, D-37077 Göttingen, Germany; ${ }^{5}$ Department of Biochemistry and Molecular Biology, University of Massachusetts Medical Center, Worcester, Massachusetts 01655, USA.

${ }^{4}$ These authors contributed equally to the work.

${ }^{8}$ Corresponding authors.

E-MAIL Phillip.Zamore@umassmed.edu (PDZ) or ttuschl@mpibpc.gwdg.de (TT); FAX (617) 258-6768.
Montgomery et al. 1998). The function of RNAi is not known, but it may represent a cellular defense against viral infection, or perhaps a post-transcriptional mechanism for regulating gene expression in response to dsRNA formed from nuclear transcripts.

The gene silencing induced by RNAi is reversible and thus does not appear to reflect a genetic change (Fire et al. 1998). Evidence that RNAi functions post-transcriptionally is as follows: dsRNA corresponding to intron sequences does not produce RNAi (Montgomery et al. 1998), and dsRNA corresponding to exon sequences does not affect pre-mRNA levels (Ngo et al. 1998). In Caenorhabditis elegans, dsRNA targeting one gene within an operon does not effect the expression of a second gene within that operon, indicating that RNAi occurs after transcription of the nuclear polycistronic RNA (Montgomery et al. 1998). In situ hybridization experiments show that dsRNA causes a specific reduction in target mRNA levels (Fire et al. 1998; Kennerdell and Carthew 1998; Misquitta and Paterson 1999; Sánchez-Alvarado and Newmark 1999). The reduced level of the mRNA targeted by dsRNA is presumed to underlie the reduction of specific gene function produced by RNAi. However, it is possible that dsRNA exerts distinct effects on mRNA translation and stability in vivo. Quantitative analyses suggest that dsRNA can specifically decrease the concentration of an mRNA by as much as $90 \%$ (Ngo et al. 1998; Lohmann et al. 1999|, although smaller effects are observed in some organisms or for particular genes (Wargelius et al. 1999). In C. elegans, RNAi has been shown to function independently of the SMG system, which was initially identified by its role in degrading 
Tuschl et al.

translationally aberrant mRNAs (Montgomery et al. 1998).

Only a few molecules of dsRNA per cell are required to produce RNAi (Fire et al. 1998; Kennerdell and Carthew 1998). The small amount of dsRNA required for silencing and the spreading of the silencing through a broad region of the organism suggests that the dsRNA either acts catalytically or is amplified (Fire 1999). Amplification of dsRNA may occur in Neurospora, in which a gene that is similar to an RNA-dependent RNA polymerase has been shown to be required for quelling (Cogoni and Macino 1999|. However, in C. elegans, replication of the dsRNA has not been detected, leading to the suggestion that the dsRNA functions catalytically (Montgomery et al. 1998). At least in C. elegans, dsRNA is efficiently transported throughout the entire organism. Remarkably, dsRNA that is fed to worms produces specific interference (Timmons and Fire 1998).

The molecular mechanisms by which dsRNA generates the RNAi effect are unknown. The recapitulation of the essential features of RNAi in vitro is a prerequisite for a biochemical analysis of the phenomenon. Here we describe gene-specific, dsRNA-mediated interference in a cell-free system derived from syncytial blastoderm Drosophila embryos. The in vitro system should complement genetic approaches to dissecting the molecular basis of RNAi.

\section{Results and Discussion}

To evaluate whether dsRNA could specifically block gene expression in vitro, we used reporter mRNAs derived from two different luciferase genes, Renilla reniformis (sea pansy) luciferase ( $R r$-Luc) and Photinus pyralis (firefly) luciferase ( $P p$-Luc), that are unrelated both in sequence and in luciferin substrate specificity. dsRNA generated from one gene was used to target that luciferase mRNA, whereas the other luciferase mRNA was an internal control cotranslated in the same reaction. dsRNAs of $\sim 500 \mathrm{bp}$ were prepared by transcription of PCR products from the $R r$-Luc and $P p$-Luc genes. Each dsRNA began $\sim 100$ bp downstream of the start of translation (Fig. 1A). Sense (ss) and anti-sense (as) RNA were transcribed in vitro and annealed to each other to produce the dsRNA (Fig. 1B). The ssRNA, asRNA, and dsRNAs were each tested for their ability to block specifically expression of their cognate mRNA but not the expression of the unrelated internal control mRNA.

The ssRNA, asRNA, or dsRNA was incubated for 10 min in a reaction containing Drosophila embryo lysate, then both $P p$-Luc and $R r$-Luc mRNAs were added and the incubation continued for an additional $60 \mathrm{~min}$. The Drosophila embryo lysate efficiently translates exogenously transcribed mRNA under the conditions used. The amounts of $P p$-Luc and $R r$-Luc enzyme activities were measured and were used to calculate ratios of either $P p$-Luc/Rr-Luc (Fig. 2A) or $R r$-Luc/Pp-Luc (Fig. 2B). To facilitate comparison of different experiments, the ratios from each experiment were normalized to the ratio ob-

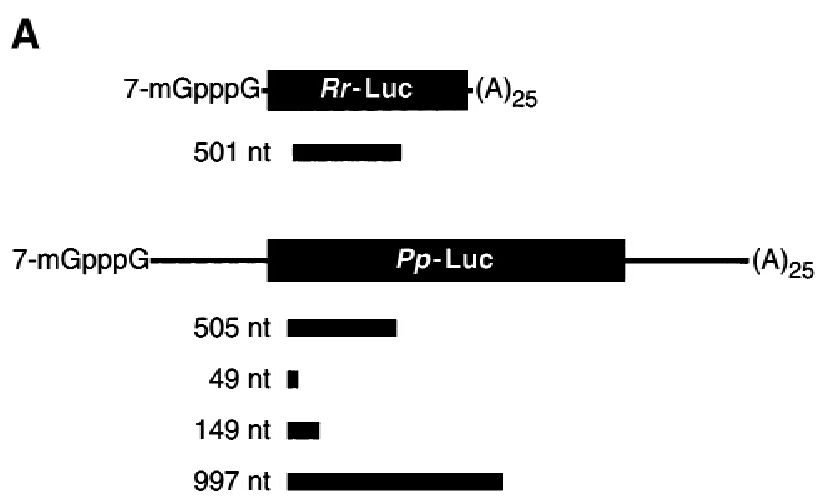

B

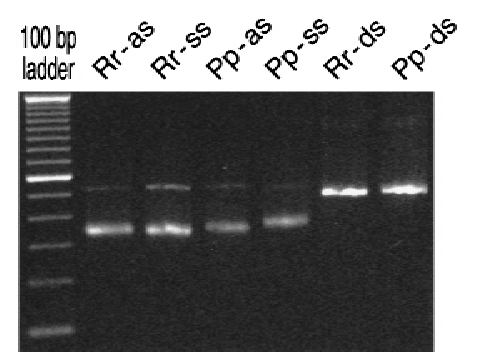

Figure 1. Reporter mRNAs and dsRNAs. $(A)$ RNAs used in this study. Lengths and positions of the ssRNA, asRNA, and dsRNAs are shown as black bars relative to the $R r$-Luc and $P p$-Luc reporter mRNA sequences. Black rectangles indicate the two unrelated luciferase coding sequences, lines correspond to the $5^{\prime}$ and 3' UTRs of the mRNAs. (B) Native gel electrophoresis of the individual $R r 501 \mathrm{nt}$ and $P p 505 \mathrm{nt}$ asRNAs and ssRNAs used to form the $R r$ and $P p$ dsRNAs.

served for a control in which buffer was added to the reaction in place of ssRNA, asRNA, or dsRNA.

Figure $2 \mathrm{~A}$ shows that a $10-\mathrm{nm}$ concentration of the 505-bp dsRNA identical to a portion of the sequence of the $P p$-Luc gene specifically inhibited expression of the $P p$-Luc mRNA but did not affect expression of the $R r$ Luc internal control. Neither ssRNA nor asRNA affected expression of $P p$-Luc or the $R r$-Luc internal control. Thus, $P p$-Luc expression was specifically inhibited by its cognate dsRNA. Conversely, a $10 \mathrm{~nm}$ concentration of the 501-bp dsRNA directed against the $R r$-Luc mRNA specifically inhibited $R r$-Luc expression but not that of the $P p$-Luc internal control (Fig. 2B). Again, comparable levels of ssRNA or asRNA had little or no effect on expression of either reporter mRNA. On average, dsRNA reduced specific luciferase expression by $70 \%$ in these experiments, in which luciferase activity was measured after a $1 \mathrm{hr}$ incubation. In other experiments in which the translational capacity of the reaction was replenished by the addition of fresh lysate and reaction components, we observed a further reduction in targeted luciferase activity relative to the internal control (data not shown).

The ability of dsRNA but not asRNA to inhibit gene expression in these lysates is not merely a consequence of the greater stability of the dsRNA (half-life $\geq 2 \mathrm{hr}$ ) 
A

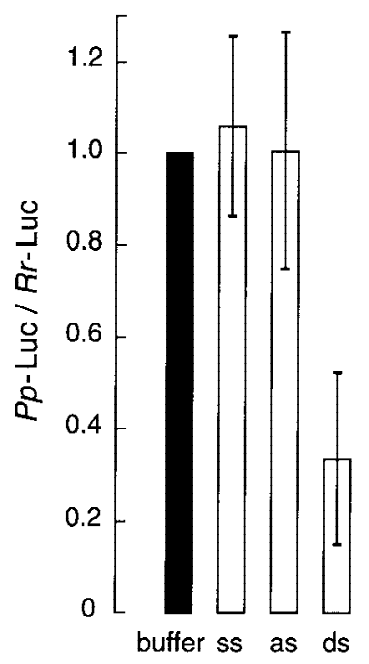

Target: $P p$-Luc mRNA
B

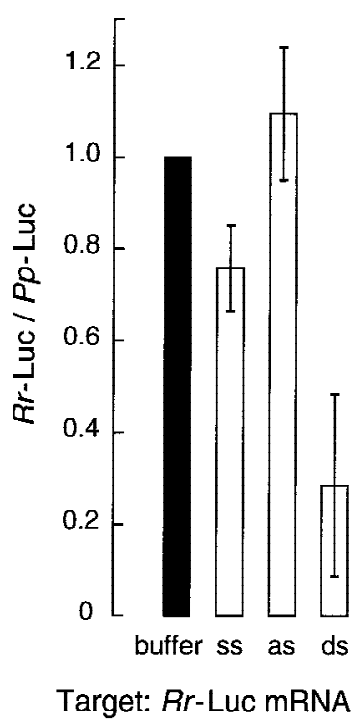

Figure 2. Gene-specific interference by dsRNA in vitro. $(A)$ Ratio of luciferase activities after targeting $50 \mathrm{pm} P p$-Luc mRNA with $10 \mathrm{~nm}$ ssRNA, asRNA, or dsRNA from the 505-bp segment of the $P p$-Luc gene. The data are the average values of seven trials \pm standard deviation. Four independently prepared lysates were used. Luciferase activity was normalized to the buffer control and so a ratio equal to one indicates no genespecific interference. $(B)$ Ratio of luciferase activities after targeting 50 pM $R r$-Luc mRNA with 10 nM ssRNA, asRNA, or dsRNA from the 501-bp segment of the $R r$-Luc gene. The data are the average values of six trials \pm standard deviation. A $R r$ Luc $/ P p$-Luc ratio equal to one indicates no gene-specific interference.

relative to the single-stranded RNAs (half-life $\sim 10 \mathrm{~min}$ ). ssRNA and asRNA transcribed with a 7-methyl guanosine cap were as stable in the lysate as uncapped dsRNA, but do not inhibit gene expression (data not shown). In contrast, dsRNA formed from the capped ssRNA and asRNA specifically blocks expression of the targeted mRNA (data not shown).

Effective RNAi in Drosophila requires the injection of $\sim 0.2$ fmole of dsRNA into a syncytial blastoderm embryo (Kennerdell and Carthew 1998; Carthew 1999). Because the average volume of a Drosophila embryo is $\sim 7.3 \mathrm{nl}$, this corresponds to an intracellular concentration of $\sim 25$ nм (Mazur et al. 1988). Gene expression in the Drosophila lysate was inhibited by a comparable concentration of dsRNA (10 nM), but lowering the dsRNA concentration 10-fold decreased the amount of specific interference (data not shown). Ten nanomolar dsRNA corresponds to a 200-fold excess of dsRNA over target mRNA added to the lysate. To test whether this excess of dsRNA might reflect a time- and/or concentrationdependent step in which the input dsRNA was converted to a form active for gene-specific interference, the effect of preincubation of the dsRNA on its ability to inhibit expression of its cognate mRNA was examined. Because the translational capacity of the lysates is significantly reduced after $30 \mathrm{~min}$ of incubation at $25^{\circ} \mathrm{C}$ (our unpub- lished observations), we wished to ensure that all factors necessary for RNAi remained active throughout the preincubation period. Therefore, every $30 \mathrm{~min}$, a reaction containing dsRNA and lysate was mixed with a fresh reaction containing unincubated lysate (Fig. 3A). After six successive serial transfers spanning $3 \mathrm{hr}$ of preincubation, the dsRNA, now diluted 64-fold relative to its original concentration, was incubated with lysate and 50 pM of target mRNA for $60 \mathrm{~min}$. Finally, the $P p$-Luc and $R r$-Luc enzyme levels were measured. For comparison, the input amount of dsRNA (10 nM) was diluted 32-fold in buffer, and its capacity to generate gene-specific dsRNA interference in the absence of any preincubation step was assessed.

The preincubation of the dsRNA in lysate significantly potentiated its capacity to inhibit specific gene expression. Whereas the dsRNA diluted 32 -fold showed

\section{A}

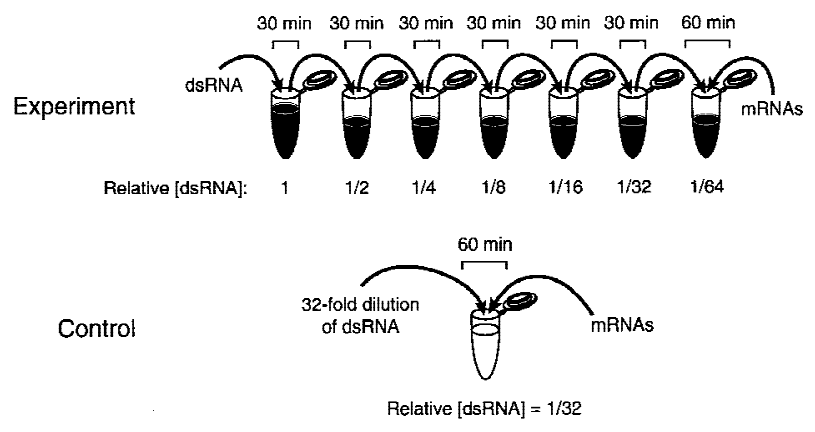

B

C
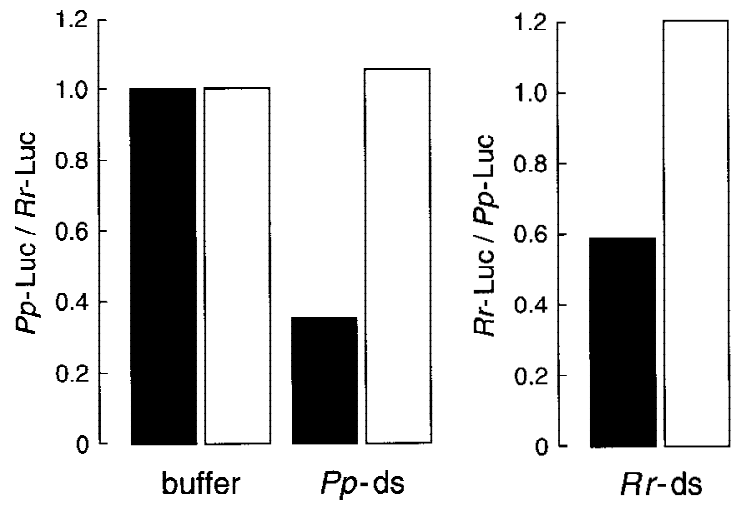

Figure 3. Incubation in the Drosophila embryo lysate potentiates dsRNA for gene-specific interference. (A) Experimental strategy. The same dsRNAs used in Fig. 2 (or buffer) was serially preincubated with twofold dilutions in six successive reactions with Drosophila embryo lysate, then tested for its capacity to block mRNA expression. As a control, the same amount of dsRNA (10 nM) or buffer was diluted directly in buffer and incubated with $P p$-Luc and $R r$-Luc mRNAs and lysate. (B) Potentiation when targeting $P p$-Luc mRNA. Black columns indicate the dsRNA or the buffer was serially preincubated; white columns correspond to a direct 32-fold dilution of the dsRNA. Values were normalized to those of the buffer controls. $(C)$ Potentiation when targeting $R r$-Luc mRNA. The corresponding buffer control is shown in $B$. 
no effect, the preincubated dsRNA was, within experimental error, as potent as undiluted dsRNA, despite having undergone a 64-fold dilution. Potentiation of the dsRNA by preincubation was observed for dsRNAs targeting both the $P p$-Luc mRNA (Fig. $3 \mathrm{~B}$ ) and the $R r$-Luc mRNA (Fig. 3C). Taking into account the 64-fold dilution, the activation conferred by preincubation allowed a 156-pM concentration of dsRNA to inhibit $50 \mathrm{pm}$ target mRNA. Higher dilutions of the activated dsRNA may be effective, but have not been tested. Although both dsRNAs tested were activated by the preincubation procedure, each fully retained its specificity to interfere with expression only of the mRNA to which it is homologous. Further study of the reactions may provide a route to identifying the mechanism of dsRNA potentiation.

One possible explanation for the observation that preincubation of the dsRNA enhances its capacity to inhibit gene expression in these lysates is that specific factors either modify and/or associate with the dsRNA. Accordingly, the addition of increasing amounts of dsRNA to the reaction might titrate such factors and decrease the amount of gene-specific interference caused by a second dsRNA of unrelated sequence. For both $P p$-Luc mRNA and $R r$-Luc mRNA, addition of increasing concentrations of the unrelated Drosophila nanos dsRNA to the reaction decreased the amount of gene-specific interference caused by dsRNA targeting the reporter mRNA (Fig. 4). None of the tested concentrations of nanos dsRNA affected the levels of translation of the untargeted mRNA, demonstrating that the nanos dsRNA specifically titrated factors involved in gene-specific interference and not components of the translational machinery. The limiting factor(s) was titrated by addition of 1000 nM dsRNA, a 200-fold excess over the $5 \mathrm{~nm}$ of dsRNA used to produce specific interference.

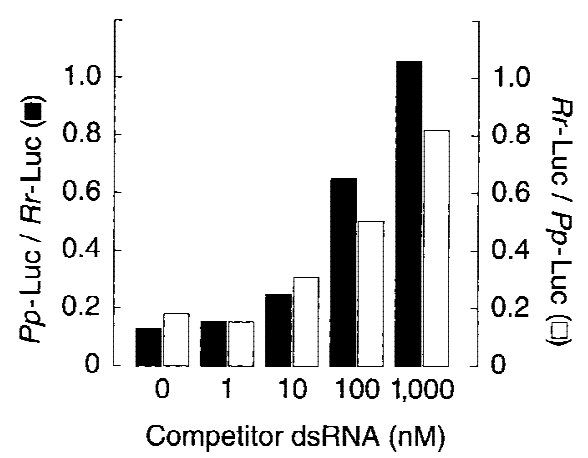

Figure 4. Effect of competitor dsRNA on gene-specific interference. Increasing concentrations of nanos dsRNA (508 bp) were added to reactions containing $5 \mathrm{~nm}$ dsRNA /the same dsRNAs used in Fig. 2) targeting Pp-Luc mRNA (black columns, left axis) or $R r$-Luc mRNA (white columns, right axis). Each reaction contained both a target mRNA $(P p$-Luc for the black columns, $R r$-Luc for the white) and an unrelated control mRNA (Rr-Luc for the black columns, $P p$-Luc for the white). Values were normalized to the buffer control (not shown). The reactions were incubated under standard conditions (see Materials and Methods).
Interference in vitro might reflect either a specific inhibition of mRNA translation or the targeted destruction of the specific mRNA. To distinguish these two possibilities, the fates of the $P p$-Luc and $R r$-Luc mRNAs were examined directly with ${ }^{32} \mathrm{P}$-radiolabeled substrates. In the absence of dsRNA, both the $P p$-Luc and $R r$-Luc mRNAs were stable in the lysates, with $\sim 75 \%$ of the input mRNA remaining after $3 \mathrm{hr}$ of incubation. (About 25\% of the input mRNA is rapidly degraded in the reaction and likely represents uncapped mRNA generated by the in vitro transcription process.) In the presence of dsRNA (10 nм, $505 \mathrm{bp}$ ) targeting the $P p$-Luc mRNA, $<15 \%$ of the $P p$-Luc mRNA remained after $3 \mathrm{hr}$ (Fig. 5A,B). As expected, the $R r$-Luc mRNA remained stable in the presence of the dsRNA targeting $P p$-Luc mRNA. Conversely, dsRNA (10 nM, $501 \mathrm{bp}$ ) targeting the $R r$-Luc mRNA caused the destruction of the Rr-Luc mRNA but had no effect on the stability of $P p$-Luc mRNA (Fig. 5C). For both mRNAs, capped asRNA has a very small effect on the stability of the target (data not shown). This effect may be caused by a small amount of dsRNA contaminating the asRNA. Low levels of dsRNA that form during in vitro transcription of asRNA cause RNAi in vivo (Fire et al. 1998). Alternatively, a small fraction of the capped asRNA could have annealed to mRNA in the reaction, creating dsRNA.

In the in vitro reaction, dsRNA specifically caused accelerated decay of the mRNA to which it is homologous, with no effect on the stability of the unrelated control mRNA. The in vitro results suggest that in vivo, at least in Drosophila, the effect of dsRNA is to destabilize the target mRNA directly, not to change the subcellular localization of the mRNA, for example, by causing it to be specifically retained in the nucleus, resulting in subsequent, nonspecific degradation.

These results are consistent with the observation that RNAi leads to reduced cytoplasmic mRNA levels in vivo, as measured by in situ hybridization (Montgomery et al. 1998) and Northern blotting (Ngo et al. 1998). Northern blot analyses in trypanosomes and hydra suggest that dsRNA typically decreases mRNA levels by $<90 \%$ (Ngo et al. 1998; Lohmann et al. 1999). The data presented here show that in vitro mRNA levels are reduced $65 \%-85 \%$ after $3 \mathrm{hr}$ incubation, an effect comparable with observations in vivo. They also agree with the finding that RNAi in C. elegans is post-transcriptional (Montgomery et al. 1998). The simplest explanation for the specific effects on protein synthesis is that it reflects the accelerated rate of RNA decay. However, the results do not exclude independent but specific effects on translation as well as stability.

In vivo, RNAi requires a minimum length of dsRNA (Ngo et al. 1998). The ability of RNA duplexes of lengths 49, 149, 505, and 997 bp (diagrammed in Fig. 1A) to target the degradation of the $P p$-Luc mRNA in vitro was assessed. In good agreement with in vivo observations, the 49-bp dsRNA was ineffective in vitro, whereas the 149bp dsRNA enhanced mRNA decay only slightly, and both the 505- and 997-bp dsRNAs caused robust mRNA degradation (Fig. 5D). 
A

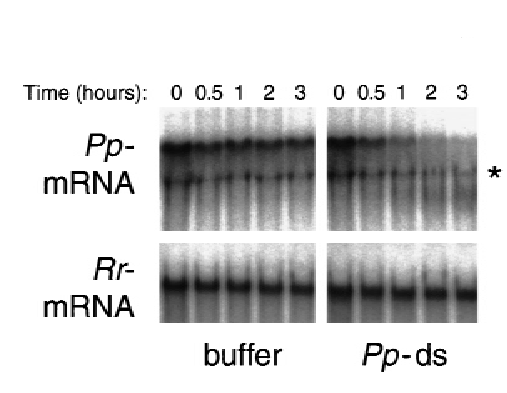

C

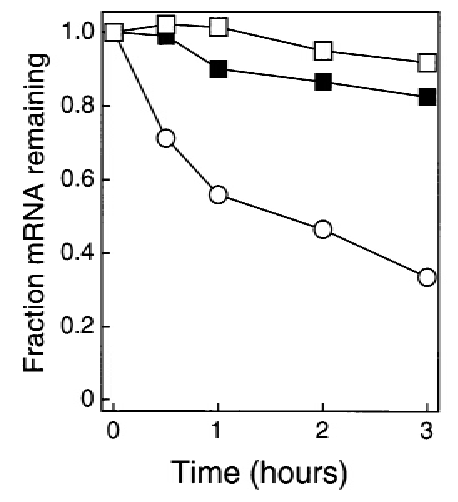

B

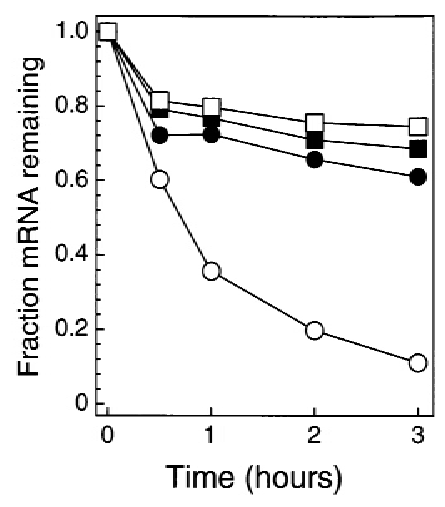

D

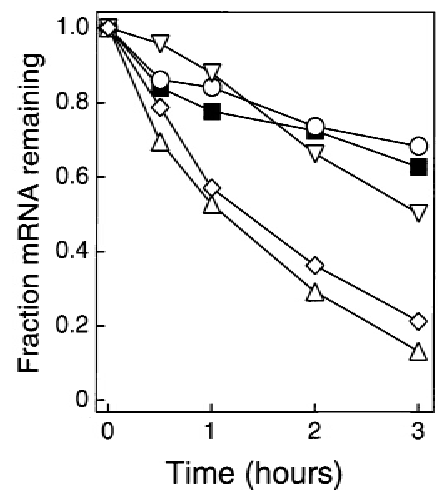

Figure 5. Effect of dsRNA on mRNA stability. (A) Stability of 10 nм $P p$-Luc mRNA or $R r$-Luc mRNA incubated in lysate with either buffer or 505-bp $P p$ dsRNA (10 nM). Samples were deproteinized after the indicated times and the ${ }^{32} \mathrm{P}$-radiolabeled mRNAs were then resolved by denaturing gel electrophoresis. The band marked with an asterisk likely results from radioactivity being swept ahead of the abundant ribosomal RNA in the lysate. $(B)$ Quantitation of the data in $A$. (Circles) $P p$-Luc mRNA; (boxes) $R r$-Luc mRNA; (filled symbols) buffer incubation; (open symbols) incubation with $P p$-dsRNA. (C) Stability of $R r$-Luc mRNA incubated with $R r$-dsRNA or $P p$-dsRNA. (口) buffer; ( $\square)$ Pp-dsRNA (10 nM); (O) Rr-dsRNA (10 nM). $(D)$ Dependence on dsRNA length. The stability of the $P p$-Luc mRNA was assessed after incubation in lysate in the presence of buffer or dsRNAs of different lengths. (口) Buffer; (O) 49-bp dsRNA (10 nM); ( $\nabla)$ 149bp dsRNA $(10 \mathrm{~nm}) ;(\triangle)$ 505-bp dsRNA $(10 \mathrm{nM}) ;(\diamond)$ 997-bp dsRNA (10 nM). Reactions were incubated under standard conditions (see Materials and Methods).
We asked whether the gene-specific interference observed in Drosophila lysates was a general property of cell-free translation systems. The effects of dsRNAs on expression of $P p$-Luc and $R r$-Luc mRNA were examined in commercially available wheat germ extracts and rabbit reticulocyte lysates. There was no effect of addition of $10 \mathrm{~nm}$ of either ssRNA, asRNA, or dsRNA on the expression of either mRNA reporter in wheat germ extracts (data not shown). In contrast, the addition of $10 \mathrm{~nm}$ of dsRNA to the rabbit reticulocyte lysate caused a profound and rapid, nonspecific decrease in mRNA stability (data not shown). For example, addition of $R r$-Luc dsRNA caused degradation of both $R r$-Luc and $P p$-Luc mRNAs within $15 \mathrm{~min}$. The same nonspecific effect was observed on addition of $P p$-Luc dsRNA. The nonspecific destruction of mRNA induced by the addition of dsRNA to the rabbit reticulocyte lysate presumably reflects the previously observed activation of RNase L by dsRNA (Clemens and Williams 1978; Williams et al. 1979; Zhou et al. 1993; Matthews 1996). Mouse cell lines lacking dsRNA-induced anti-viral pathways have been described recently (Zhou et al. 1999) and may be useful in the search for mammalian RNAi. If RNAi exists in mammals, as might be predicted from the presence of RNAilike phenomena in invertebrates, plants, and fungi, as well as the recent report of RNAi in the vertebrate Danio rerio (zebrafish; Wargelius et al. 1999), it is likely ob- scured by the rapid induction by dsRNA of nonspecific antiviral responses.

dsRNA-targeted destruction of specific mRNA is characteristic of RNAi, which has been observed in vivo in many organisms, including Drosophila. The system described above recapitulates in a reaction in vitro many aspects of RNAi. The targeted mRNA is specifically degraded, whereas unrelated control mRNAs present in the same solution are not affected. The process is most efficient with dsRNAs $>150 \mathrm{bp}$ in length. The dsRNA-specific degradation reaction in vitro is probably general to many, if not all, mRNAs, as it was observed by use of two unrelated genes.

The magnitude of the effects we observe on mRNA stability in vitro are comparable with those reported in vivo (Ngo et al. 1998; Lohmann et al. 1999). However, the reaction in vitro requires an excess of dsRNA relative to mRNA. In contrast, a few molecules of dsRNA per cell can inhibit gene expression in vivo (Fire et al. 1998; Kennerdell and Carthew 1998). The difference between the stoichiometry of dsRNA to target mRNA in vivo and in vitro should not be surprising in that most in vitro reactions are less efficient than their corresponding in vivo processes. Interestingly, incubation of the dsRNA in the lysate greatly potentiated its activity for RNAi, indicating that it is either modified or becomes associated with other factors or both. Perhaps a small number 
of molecules is effective in inhibiting the targeted mRNA in vivo because the injected dsRNA has been activated by a process similar to that reported here for RNAi in Drosophila lysates. The nature of this activation process, the mechanism of destruction of the targeted mRNAs, and the identification of cellular factors essential for RNAi await further experiments.

\section{Materials and methods}

\section{RNAs}

$R r$-Luc mRNA consisted of the 926-nucleotide $R r$ luciferase coding sequence flanked by 25 nucleotides of $5^{\prime}$ untranslated sequence from the pSP64 plasmid polylinker and 25 nucleotides of $3^{\prime}$ untranslated sequence consisting of 19 nucleotides of pSP64 plasmid polylinker sequence followed by a 6-nt SacI site. $P P$-Luc mRNA contained the 1653-nt Pp luciferase coding sequence with a $K p n I$ site introduced immediately before the $P p$ luciferase stop codon. The $P p$ coding sequence was flanked by $5^{\prime}$ untranslated sequences consisting of $21 \mathrm{nt}$ of pSP64 plasmid polylinker followed by $512 \mathrm{nt}$ of the $5^{\prime}$ untranslated region (UTR) from the Drosophila hunchback mRNA and 3' untranslated sequences consisting of the 562-nt hunchback 3' UTR followed by a 6-nt SacI site. The hunchback 3' UTR sequences used contained six G-to-U mutations that disrupt function of the Nanos Response Elements in vivo and in vitro (D. Chagnovich, P.D. Zamore, R. Lehman, and D.P. Bartel, unpubl.). Both reporter mRNAs terminated in a $25-\mathrm{nt}$ poly(A) tail encoded in the transcribed plasmid. For both $R r$-Luc and $P p$-Luc mRNAs, the transcripts were generated by run-off transcription from plasmid templates cleaved at an NsiI site that immediately followed the 25-nt-encoded poly(A) tail. To ensure that the transcripts ended with a poly(A) tail, the NsiI-cleaved transcription templates were resected with T4 DNA Polymerase in the presence of dNTPs. The SP6 mMessage mMachine kit (Ambion) was used for in vitro transcription. With this kit, $~ 80 \%$ of the resulting transcripts are 7-methyl guanosine capped. ${ }^{32} \mathrm{P}$-radiolabeling was accomplished by including $\left[\alpha-{ }^{32} \mathrm{P}\right] \mathrm{UTP}$ in the transcription reaction.

For Pp-Luc, ssRNA, asRNA, and dsRNA corresponded to positions 93-597 relative to the start of translation, yielding $a$ 505- $b p d s R N A$. For $R r$-Luc, asRNA, ssRNA, and dsRNA corresponded to positions 118-618 relative to the start of translation, yielding a 501-bp dsRNA. The Drosophila nanos competitor dsRNA corresponded to positions 122-629 relative to the start of translation, yielding a 508-bp dsRNA. ssRNA, asRNA, and dsRNA (diagrammed in Fig. 1A) were transcribed in vitro with T7 RNA polymerase from templates generated by the PCR. After gel purification of the T7 RNA transcripts, residual DNA template was removed by treatment with RQ1 DNase (Promega). The RNA was extracted with phenol and chloroform, and then precipitated and dissolved in water.

\section{RNA annealing and native gel electrophoresis}

ssRNA and asRNA $(0.5 \mu \mathrm{M})$ in $10 \mathrm{~mm}$ Tris- $\mathrm{HCl}(\mathrm{pH} 7.5)$ with 20 $\mathrm{mm} \mathrm{NaCl}$ were heated to $95^{\circ} \mathrm{C}$ for $1 \mathrm{~min}$, then cooled and annealed at room temperature for $12-16 \mathrm{hr}$. The RNAs were precipitated and resuspended in lysis buffer (below). To monitor annealing, RNAs were electrophoresed in a $2 \%$ agarose gel in TBE buffer and stained with ethidium bromide (Sambrook et al. 1989).

\section{Lysate preparation}

Zero- to 2-hr-old embryos from Oregon R flies were collected on yeasted molasses agar at $25^{\circ} \mathrm{C}$. Embryos were dechorionated for 4-5 $\mathrm{min}$ in $50 \%$ (vol/vol) bleach, washed with water, blotted dry, and transferred to a chilled Potter-Elvehjem tissue grinder (Kontes). Embryos were lysed at $4^{\circ} \mathrm{C}$ in $1 \mathrm{ml}$ of lysis buffer (100 $\mathrm{mm}$ potassium acetate, $30 \mathrm{~mm}$ HEPES-KOH at $\mathrm{pH} 7.4,2 \mathrm{~mm}$ magnesium acetate) containing $5 \mathrm{~mm}$ dithiothreitol (DTT) and 1 $\mathrm{mg} / \mathrm{ml}$ Pefabloc SC (Boehringer Mannheim) per gram of damp embryos. The lysate was centrifuged for $25 \mathrm{~min}$ at $14,500 \mathrm{~g}$ at $4^{\circ} \mathrm{C}$, and the supernatant flash frozen in aliquots in liquid nitrogen and stored at $-80^{\circ} \mathrm{C}$.

\section{Reaction conditions}

Lysate preparation and reaction conditions were derived from those described by Hussain and Leibowitz (1986). Reactions contained $50 \%$ (vol/vol) lysate, mRNAs (10-50 pM final concentration), and $10 \%$ (vol/vol) lysis buffer containing the ssRNA, asRNA, or dsRNA (10 nm final concentration). Each reaction also contained $10 \mathrm{~mm}$ creatine phosphate, $10 \mu \mathrm{g} / \mathrm{ml}$ creatine phosphokinase, $100 \mu \mathrm{M}$ GTP, $100 \mu \mathrm{M}$ UTP, $100 \mu \mathrm{M}$ CTP, $500 \mu \mathrm{M}$ ATP, $5 \mathrm{~mm}$ DTT, $0.1 \mathrm{U} / \mu \mathrm{L}$ RNasin (Promega), and $100 \mu \mathrm{M}$ of each amino acid. The final concentration of potassium acetate was adjusted to $100 \mathrm{~mm}$. For standard conditions, the reactions were assembled on ice and then preincubated at $25^{\circ} \mathrm{C}$ for $10 \mathrm{~min}$ before adding mRNA. After adding mRNAs, the incubation was continued for an additional $60 \mathrm{~min}$. The 10-min preincubation step was omitted for the experiments in Figures 3 and 5 . Reactions were quenched with 4 volumes of 1.25× Passive Lysis Buffer (Promega). $P p$ and $R r$ luciferase activity was detected in a Monolight 2010 Luminometer (Analytical Luminescence Laboratory) with the Dual-Luciferase Reporter Assay System (Promega).

\section{RNA stability}

Reactions with ${ }^{32} \mathrm{P}$-radiolabeled mRNA were quenched by the addition of 40 volumes of $2 \times \mathrm{PK}$ buffer $(200 \mathrm{~mm}$ Tris- $\mathrm{HCl}$ at $\mathrm{pH}$ 7.5, 25 mм EDTA, $300 \mathrm{~mm} \mathrm{NaCl}, 2 \% \mathrm{wt} / \mathrm{vol}$ sodium dodecyl sulfate). Proteinase K (E.M. Merck; dissolved in water) was added to a final concentration of $465 \mu \mathrm{g} / \mathrm{ml}$. The reactions were then incubated for $15 \mathrm{~min}$ at $65^{\circ} \mathrm{C}$, extracted with phenol/chloroform/isoamyl alcohol $(25: 24: 1)$, and precipitated with an equal volume of isopropanol. Reactions were analyzed by electrophoresis in a formaldehyde/agarose $(0.8 \% \mathrm{wt} / \mathrm{vol})$ gel (Sambrook et al. 1989). Radioactivity was detected by exposing the agarose gel [dried under vacuum onto Nytran Plus membrane (Amersham)] to an image plate (Fujix) and quantified with a Fujix Bas 2000 and Image Gauge 3.0 (Fujix) software.

\section{Commercial lysates}

Untreated rabbit reticulocyte lysate (Ambion) and wheat germ extract (Ambion) reactions were assembled according to the manufacturer's directions. dsRNA was incubated in the lysate at $27^{\circ} \mathrm{C}$ (wheat germ) or $30^{\circ} \mathrm{C}$ (reticulocyte lysate) for $10 \mathrm{~min}$ prior to the addition of mRNAs.

\section{Acknowledgments}

We thank Danny Chagnovich for the generous gift of the luciferase reporter plasmids. We also thank Terri Orr-Weaver for providing fly resources, Marlene Castle for maintaining population cages, and Jen Cook-Chrysos for help in preparing the figures. P.D.Z. was supported by a Charles H. Hood fellowship. Support for this work was provided to D.P.B. by the Searle 
Scholars Program/The Chicago Community Trust and to P.A.S. by the National Institutes of Health through a United States Public Health Service MERIT award, by the National Science Foundation, and partially by the National Cancer Institute through a Cancer Center Support core grant.

The publication costs of this article were defrayed in part by payment of page charges. This article must therefore be hereby marked "advertisement" in accordance with 18 USC section 1734 solely to indicate this fact.

\section{References}

Bahramian, M.B. and H. Zarbl. 1999. Transcriptional and posttranscriptional silencing of rodent alpha1(I) collagen by a homologous transcriptionally self-silenced transgene. Mol. Cell. Biol. 19: 274-283.

Baulcombe, D.C. 1999. Fast forward genetics based on virusinduced gene silencing. Curr. Opin. Plant. Biol. 2: 109-113.

Carthew, R. 1999. wwwl.pitt.edu/ carthew/manual/ RNAi Protocol.html

Clemens, $\bar{M}$. and B. Williams. 1978. Inhibition of cell-free protein synthesis by pppA2'p5'A2'5'A: a novel oligonucleotide synthesized by interferon-treated L cell extracts. Cell 13: $565-572$.

Cogoni, C. and G. Macino. 1999. Gene silencing in Neurospora crassa requires a protein homologous to RNA-dependent RNA polymerase. Nature 399: 166-169.

Cogoni, C., J.T. Irelan, M. Schumacher, T.J. Schmidhauser, E.U. Selker, and G. Macino. 1996. Transgene silencing of the al-1 gene in vegetative cells of Neurospora is mediated by a cytoplasmic effector and does not depend on DNA-DNA interactions or DNA methylation. EMBO I. 15: 3153-3163.

Fire, A. 1999. RNA-triggered gene silencing. Trends Genet. 15: 358-363.

Fire, A., S. Xu, M.K. Montgomery, S.A. Kostas, S.E. Driver, and C.C. Mello. 1998. Potent and specific genetic interference by double-stranded RNA in Caenorhabditis elegans. Nature 391: 806-811.

Hunter, C.P. 1999. A touch of elegance with RNAi. Curr. Biol. 9: R440-442.

Hussain, I. and M.J. Leibowitz. 1986. Translation of homologous and heterologous messenger RNAs in a yeast cell-free system. Gene 46: 13-23.

Kennerdell, J.R. and R.W. Carthew. 1998. Use of dsRNA-mediated genetic interference to demonstrate that frizzled and frizzled 2 act in the wingless pathway. Cell 95: 1017-1026.

Lohmann, J.U., I. Endl, and T.C. Bosch. 1999. Silencing of developmental genes in hydra. Dev. Biol. 214: 211-214.

Matthews, M. 1996. Interactions between viruses and the cellular machinery for protein synthesis. In Translational control (ed. J. Hershey, M. Mathews, and N. Sonenberg), pp. 505-548. Cold Spring Harbor Laboratory Press, Cold Spring Harbor, NY.

Mazur, P., U. Schneider, K. Jacobsen, and A. Mahowald. 1988. Survival of intact Drosophila eggs at various stages of embryonic development as a function of the extent of dehydration and of intraembryonic freezing. Cryobiology 25: 543544.

Misquitta, L. and B.M. Paterson. 1999. Targeted disruption of gene function in Drosophila by RNA interference (RNA-i): A role for nautilus in embryonic somatic muscle formation. Proc. Natl. Acad. Sci. 96: 1451-1456.

Montgomery, M.K. and A. Fire. 1998. Double stranded RNA as a mediator in sequence-specific genetic silencing and co-suppression. Trends Genet. 14: 255-258.
Montgomery, M.K., S. Xu, and A. Fire. 1998. RNA as a target of double-stranded RNA-mediated genetic interference in Caenorhabditis elegans. Proc. Nat1. Acad. Sci. 95: 15502-15507.

Ngo, H., C. Tschudi, K. Gull, and E. Ullu. 1998. Doublestranded RNA induces mRNA degradation in Trypanosoma brucei. Proc. Nat1. Acad. Sci. 95: 14687-14692.

Pal-Bhadra, M., U. Bhadra, and J.A. Birchler. 1997. Cosuppression in Drosophila: Gene silencing of Alcohol dehydrogenase by white-Adh transgenes is Polycomb dependent. Cell 90: 479-490.

. 1999. Cosuppression of nonhomologous transgenes in Drosophila involves mutually related endogenous sequences. Cell 99: 35-46.

Sambrook, J., E. Fritsch, and T. Maniatis. 1989. Molecular cloning. Cold Spring Harbor Laboratory Press, Cold Spring Harbor, NY.

Sánchez-Alvarado, A. and P.A. Newmark. 1999. Doublestranded RNA specifically disrupts gene expression during planarian regeneration. Proc. Nat1. Acad. Sci. 96: 5049-5054.

Sharp, P.A. 1999. RNAi and double-strand RNA. Genes \& Dev. 13: $139-141$.

Timmons, L. and A. Fire. 1998. Specific interference by ingested dsRNA. Nature 395: 854.

Vaucheret, H., C. Beclin, T. Elmayan, F. Feuerbach, C. Godon, J.B. Morel, P. Mourrain, J.C. Palauqui, and S. Vernhettes. 1998. Transgene-induced gene silencing in plants. Plant $J$. 16: 651-659.

Wargelius, A., S. Ellingsen, and A. Fjose. 1999. Double-stranded RNA induces specific developmental defects in zebrafish embryos. Biochem. Biophys. Res. Commun. 263: 156-161.

Waterhouse, P.M., M.W. Graham, and M.B. Wang. 1998. Virus resistance and gene silencing in plants can be induced by simultaneous expression of sense and antisense RNA. Proc. Nat1. Acad. Sci. 95: 13959-13964.

Williams, B.R., C.S. Gilbert, and I.M. Kerr. 1979. The respective roles of the protein kinase and pppA2'p5'A2'p5'A-activated endonuclease in the inhibition of protein synthesis by double stranded RNA in rabbit reticulocyte lysates. Nucleic Acids Res. 6: 1335-1350.

Zhou, A., B. Hassel, and R. Silverman. 1993. Expression cloning of 2-5A-dependent RNAase: A uniquely regulated mediator of interferon action. Cell 72: 753-765.

Zhou, A., J.M. Paranjape, S.D. Der, B.R. Williams, and R.H. Silverman. 1999. Interferon action in triply deficient mice reveals the existence of alternative antiviral pathways. $\mathrm{Vi}$ rology 258: 435-440. 


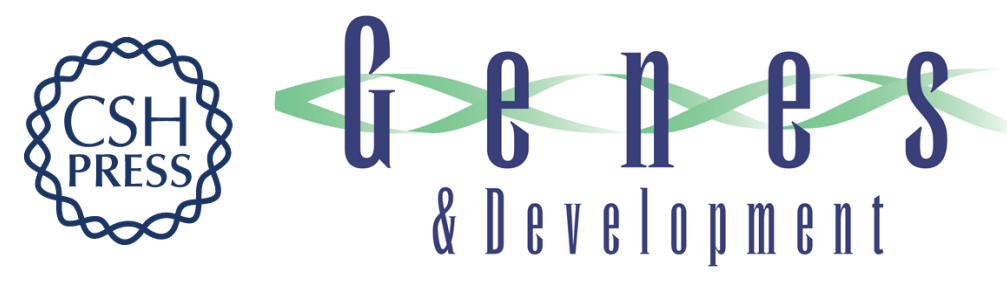

\section{Targeted mRNA degradation by double-stranded RNA in vitro}

Thomas Tuschl, Phillip D. Zamore, Ruth Lehmann, et al.

Genes Dev. 1999, 13:

References This article cites 27 articles, 7 of which can be accessed free at:

http://genesdev.cshlp.org/content/13/24/3191.full.html\#ref-list-1

License

Email Alerting

Receive free email alerts when new articles cite this article - sign up in the box at the top Service right corner of the article or click here.

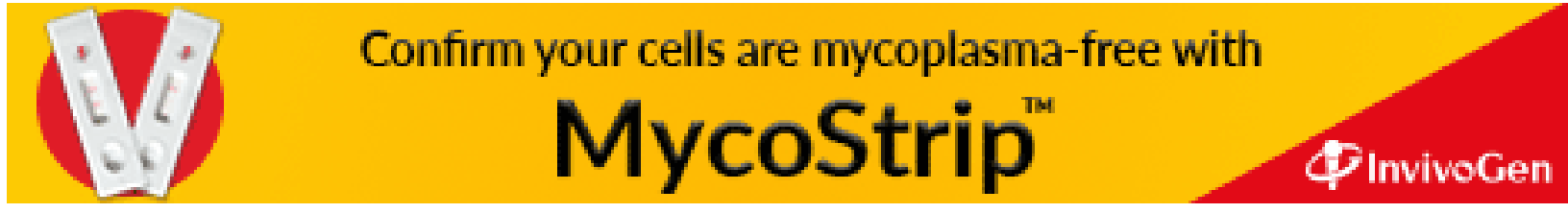

